\title{
EXPERIMENTAL AND SIMULATION STUDIES TO DETERMINE THE EFFECTIVE OCTANE NUMBER IN AN ENGINE FUELLED WITH ETHANOL AND GASOLINE
}

\author{
M. Sai Yashwanth ${ }^{1 *}$, T. Venugopal ${ }^{2}$ and A. Ramesh $^{1}$ \\ ${ }^{1}$ Department of Mechanical Engineering, Indian Institute of Technology Madras, \\ Chennai, 600036, India. \\ *E-mail: yashwanth9121@gmail.com \\ Phone: +919176111619 \\ ${ }^{2}$ Faculty of Mechanical and Building Sciences, VIT University, \\ Chennai, 600127, India.
}

\begin{abstract}
Alcohols are widely used along with gasoline owing to their superior antiknock properties. Engine knocking depends on both fuel properties and operating conditions. The Research and Motor Octane Numbers widely used to characterize antiknock potential are calculated under specific operating conditions. In this work, a method that incorporates the effects of actual operating conditions is developed, used to determine the antiknock potential when ethanol and gasoline are used in a port fuel injected engine using simultaneous and pre-blended injection modes. Experimental results are used to build and validate an analytical model of the engine which is used to study the antiknock benefits in terms of "Effective Octane Number" $\left(\mathrm{ON}_{\mathrm{Eff}}\right)$. Experiments are conducted using a newly developed injection system which utilizes separate injectors for ethanol and gasoline. This method could capture the effects of engine operating conditions in calculating antiknock benefits. Higher ethanol fractions showed better antiknock capabilities. $\mathrm{ON}_{\mathrm{Eff}}$ increases from 90 to 105 units when the ethanol quantity is increased from 0 to $100 \%$ by mass, but the effect diminishes after $50 \%$. Hence, considering antiknock benefits, the use of 50\% ethanol in gasoline is recommended. $\mathrm{ON}_{\mathrm{Eff}}$ of the pre-blended injection case was only 0.8 units higher, indicating the similar antiknock potential of both injection strategies.
\end{abstract}

Keywords: Alternative fuels; ethanol-gasoline blends; knock; octane number.

\section{INTRODUCTION}

Downsizing the engine and reducing fuel consumption and emissions are the major goals in the field of internal combustion engines today [1]. Heywood [2], and Venugopal and Ramesh [3] have shown that alternative fuels like ethanol, with its better antiknock quality, higher flame velocity, higher latent heat of vaporization and wider flammability limits when compared to gasoline, help in achieving the above goals. The use of ethanol enables increased power output without knock on account of its high octane number and the charge cooling effect that is produced due to its high latent heat [4-8]. Injecting alcohol directly into the cylinder while gasoline is injected into the manifold is reported to mitigate knock [6, 9-11]. This system allows an increase of the compression ratio, which in turn reduces the specific fuel consumption. The antiknock quality of a fuel is usually quantified through either the Research Octane Number 
(RON) or the Motor Octane Number (MON). Higher values of these octane numbers imply a better antiknock quality of the fuel $[12,13]$. RON and MON are obtained through measurements on a Centre for Fuel Research (CFR) engine under specified operating conditions as shown in Table 1 [14]. However, actual operating conditions differ from these conditions. Parameters such as charge cooling, wall heat transfer, spark timing etc. affect knocking. The antiknock benefits can be studied in a comprehensive manner if they include the actual operating conditions. An effective octane number concept introduced by Kasseris and Heywood [4], [5] includes the actual engine operating conditions by involving the pressure and temperatures of unburned charge to quantify knock by means of the $\mathrm{ON}_{\mathrm{Eff}}$.

Table 1.Test conditions for RON and MON.

\begin{tabular}{lll}
\hline \multicolumn{1}{c}{ Operating condition } & \multicolumn{1}{c}{ RON } & \multicolumn{1}{c}{ MON } \\
\hline Engine speed (RPM) & 600 & 900 \\
Intake air temperature $\left({ }^{\circ} \mathrm{C}\right)$ & 51.7 & 38 \\
Intake mixture temperature $\left({ }^{\circ} \mathrm{C}\right)$ & - & 149 \\
Spark timing & $13^{\circ}$ crank angle before TDC & variable \\
Compression ratio (adjusted to) & heavy knock & medium, light knock \\
\hline
\end{tabular}

To incorporate the actual engine operating conditions, experiments were conducted on a new dual-injection system with two separate injectors in the intake port, one for gasoline and the other for ethanol. This system enables an online fuel ratio (percentage of the amount of ethanol injected to total amount of fuel injected by mass) variation based on the operating condition, which is the major advantage. Also, experiments were conducted by injecting a pre-blended mixture using a single injector to compare the effect of different injection strategies. These experiments are outlined in greater detail in Venugopal and Ramesh [3]. Data obtained by conducting these experiments was used along with a 1-D analytical engine simulation model built in

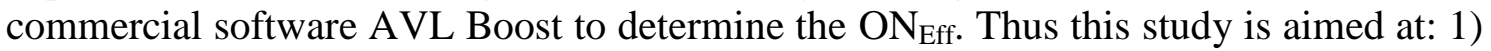
developing a method which incorporates the actual engine operating conditions to determine the antiknock potential of alcohol-gasoline blends; 2) using this method to determine the antiknock benefits when ethanol and gasoline are used in a port fuel injected engine; and 3) comparing the antiknock benefits of the dual injection system with conventional pre-blended single injection system.

\section{METHODS AND MATERIALS}

\section{Concept of Effective Octane Number}

In SI engines, knocking occurs when the unburned charge auto-ignites before the flame ignites it. This happens when the unburned charge attains a thermodynamic state at which it can auto-ignite, i.e., reaches a high temperature and also stays long enough at that condition. Assuming a single step auto-ignition reaction of the form:

$$
X+Y \rightarrow Z
$$

where $X$ is fuel, $Y$ is oxygen and $Z$ is the combustion product. The rate of reaction for a first order reaction using the Arrhenius equation for rate constant gives: 


$$
\frac{d[z]}{d t}=A * e^{\frac{-E_{a}}{R T}} *[x]^{f} *[y]^{g}
$$

where $[x]$ denotes the concentration of any specie $x, t$ is time, $A$ is the pre-exponential factor, $E_{a}$ is the activation energy, $R$ is the universal gas constant, $T$ is the temperature and $f, g$ the orders of reaction with respect to $X, Y$ respectively. By relating the reactant concentrations to pressure, Eq.(2) becomes

$$
\frac{d[z]}{d t}=W *[z] * p^{n} * e^{\frac{-B}{T}}
$$

where $W, n, B$ are constants and $\mathrm{P}$ is the pressure. The concentration of $z,[z]$ has to reach a critical concentration $\left([z]_{\text {critical }}\right)$ for auto-ignition. By integratingEq.(3), the time required for auto-ignition can be obtained. Assuming $P, T$ to be constant with time, the time required for auto-ignition ' $\tau$ 'can be obtained as:

$$
\tau=C * p^{-n} * e^{\frac{B}{T}}
$$

The constants $C, n, B$ are fuel-dependent. Since in an internal combustion engine the pressures and temperatures of the unburned charge vary with time, these changes are incorporated using a cumulative integration approach used by Livengood and $\mathrm{Wu}$ [15], which is given as:

$$
\int_{0}^{t_{c}} \frac{d t}{\tau}=\int_{0}^{t_{c}} \frac{d t}{\tau=C * p^{-n} * e^{\frac{B}{T}}}
$$

This assumes step-wise integration up to $t_{c}$, the time required for auto-ignition of unburned charge. If the pressures and temperatures used in the integral are values obtained for the knock onset condition and the integral limits are the start of combustion and end of combustion, this integral will be equal to one. In other words, knocking can be said to occur when

$$
\int_{0}^{t_{c}} \frac{d t}{\tau}=1
$$

Douaud and Eyzat [14] have proposed a correlation for auto-ignition as given below through experiments on primary reference fuels:

$$
\tau=17.68 *\left(\frac{O N}{100}\right)^{3.402} * p^{-1.7} * e^{\frac{3800}{T}}
$$


Using this correlation in Eq.(6) gives:

$$
1=\int_{0}^{t_{c}} \frac{d t}{\tau=17.68 *\left(\frac{O N}{100}\right)^{3.402} * p^{-1.7} * e^{\frac{3800}{T}}}
$$

The above equation has been used by Kasseris and Heywood [5] for ethanolgasoline blends in port fuel injection and direct injection configurations. Using the pressure and temperature histories of the unburned charge for just knocking conditions, the $\mathrm{ON}$ in the equation was varied until the integral reached unity. The thus obtained $\mathrm{ON}$ was termed the Effective Octane Number $\left(\mathrm{ON}_{\mathrm{Eff}}\right)$. For each fuel blend and injection strategy, this $\mathrm{ON}_{\mathrm{Eff}}$ was obtained for varying operating conditions (intake temperatures and loads). A similar approach has been used here to obtain the $\mathrm{ON}_{\text {Eff }}$ of ethanol gasoline blends in a dual-injection system. An analytical model of the engine built in AVL Boost facilitates the calculation of this effective octane number. The model built and used for this study is described below in detail.

\section{Experimental Set-up and Experiments}

Experiments were conducted on a single cylinder automotive spark ignition engine at a constant speed of $3000 \mathrm{rpm}$. The technical specifications of the engine used for the experiments are listed in Table 2. A modified intake manifold with two fuel injectors, one for gasoline and the other for ethanol, was used to control the fuel ratio. The engine was coupled to an eddy current dynamometer containing a closed loop speed controller to enable operation at constant speed and also provide torque measurement. Air flow rate was measured using a roots type flow meter and fuel flow rates were measured on a mass basis by using precision weighing balances. Cylinder pressure data on an angle basis was obtained by measuring the cylinder pressure with a flush-mounted piezoelectric pressure transducer and crank-angle data using an angle encoder. Exhaust gas temperature (EGT) was measured by using a K-type thermocouple located in the exhaust port. These measured data were used to build and validate the simulation model.

Table 2. Technical specifications of engine.

\begin{tabular}{ll}
\hline Engine type & Single cylinder, 4-stroke, SI \\
Bore x stroke & $62 \mathrm{~mm}$ x 66 mm \\
Connecting rod length & $120 \mathrm{~mm}$ \\
Displacement volume & $200 \mathrm{cc}$ \\
Compression ratio & $9.4: 1$ \\
\hline
\end{tabular}

As mentioned earlier, the ethanol and gasoline were injected into the intake port of the engine simultaneously through two injectors for seven different fuel ratios by using a real-time engine controller. Experiments were also conducted by injecting a preblended mixture of ethanol and gasoline for a single fuel ratio $(50 \%$ of both fuels by mass) using a single injector. The experimental set-up used is described in the next section. The ratio of ethanol was varied while the overall equivalence ratio was always maintained at unity and the throttle was fully open. The spark timing was adjusted at 
each operating fuel ratio (mass of ethanol to the total mass of ethanol and gasoline) so that the engine just knocks. Real-time inspection of the cylinder pressure signals on an oscilloscope revealed the onset of knock. A cylinder pressure trace of 100 cycles was recorded using a high-speed data acquisition system on the crank angle basis at this knock onset condition. The ensemble average cylinder pressure of 100 cycles was then processed to yield the heat release rate. Individual cycles were scanned to pick the knocking cycles, which were then used to identify the crank angle of knock onset. This experimentally obtained heat release rate was used to obtain the constants in the Vibe function. These constants were then used in the one-dimensional simulation model, namely AVL Boost, as explained later, to calculate the $\mathrm{ON}_{\mathrm{Eff}}$. This $\mathrm{ON}_{\mathrm{Eff}}$ obtained through experimental data on the engine equipped with the dual-injection system at seven fuel ratios is compared with the octane numbers of similar blends of ethanol and gasoline obtained by Anderson, Leone [1]. The effective octane number for the preblended injection case was compared to that obtained in the simultaneous injection case to study differences in their antiknock potentials.

\section{Description of the 1-D Analytical Engine Cycle Simulation Model}

An analytical model was built in AVL Boost, which is a 1-D engine cycle simulation tool. The model was built by combining elements such as pipes, injector, cylinder, system boundaries and measuring points. Table 3 lists the various elements used and Figure 1 depicts the graphical representation of the model. These elements require geometrical, flow and thermal inputs to represent the actual engine operation. Geometrical input parameters were obtained from measurements, while inputs like friction coefficients are obtained from literature or related tables present in Boost [16], $[17,18]$. In the intake system, the coefficients of discharge $\left(C_{d}\right)$ at the pipe contractions and expansions and the pipe wall temperatures were tuned to match the experimentally obtained volumetric efficiency of the engine while using gasoline. The $\mathrm{C}_{\mathrm{d}}$ values used for flow through the ports with respect to valve lift were experimentally obtained through studies which were not a part of this work. With every fuel ratio, only the port wall temperatures were suitably modified to match the experimentally obtained volumetric efficiency. Also with every fuel ratio, the combustion input to the model was provided in the form of the Vibe function.

Table 3. General inputs required to build the 1-D analytical model.

\begin{tabular}{ll}
\hline Element & Denoted in Figure 1 by \\
\hline Engine & E1 \\
Injector & I1 \\
Pipe & $1,2,3,4,5,6,7,8,9,10,11,12$ \\
Plenum & PL1, PL2, PL3 \\
Cylinder & C1 \\
Restrictors & R1, R2 \\
System boundary & SB1, SB2 \\
Measuring point & MP $x(x$ denotes the number $)$ \\
\hline
\end{tabular}

The Vibe function expresses the mass burn fraction (MBF) as a function of the crank angle and Vibe parameters given as: 


$$
x=1-e^{\left\{-a\left(\frac{\alpha-\alpha_{o}}{\Delta \alpha}\right)\right\}^{(m+1)}}
$$

where $x=$ mass burn fraction; $\alpha=$ crank angle; $\alpha_{\circ}=$ start of combustion (SOC) $\Delta \alpha=$ combustion duration (CD); $a=$ efficiency parameter; $m=$ shape parameter

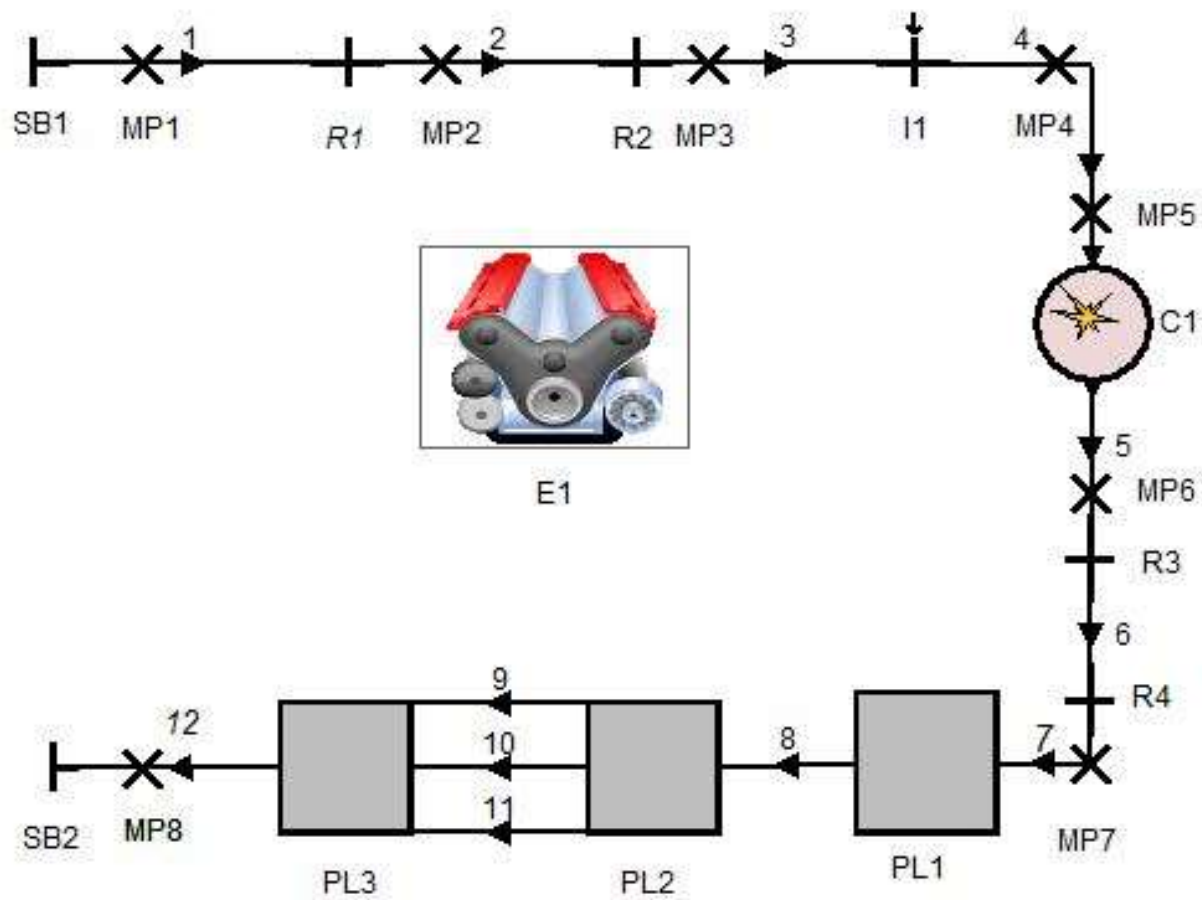

Figure 1. Graphical representation of the analytical model built in AVL Boost.

Experimental cylinder average pressure traces at knock onset conditions were used to calculate the heat release rate (HRR) by applying the first law of thermodynamics. From the HRR, the mass burn fraction (MBF) was obtained. This MBF data was the required input for the 1-D simulation code in the form of Eq. (9.) by means of Vibe parameters. A crank angle at 5\% MBF was chosen as the start of combustion and a crank angle at $95 \%$ MBF was chosen as the end of combustion. ' $a$ ' was assumed to be 6.7, which implies that $99.98 \%$ of the fuel takes part in combustion. In this way SOC, CD, and ' $a$ ' were obtained and a least square exponential fit of the MBF data was performed in LabVIEW ${ }^{\mathrm{tm}}$ to provide the remaining Vibe parameter, i.e., $\mathrm{m}$, the shape parameter which indicates the shape or slope of the MBF curve. The slope of the MBF curve provides the rate at which fuel is consumed. From Eq. (9.), it can be inferred that when keeping all other parameters constant, decreasing the value of $\mathrm{m}$ increases the value of MBF. This implies that the rate of combustion is faster.

Figure 2 shows the obtained values of the shape parameter $(\mathrm{m})$ with different fuel ratios. The value of $m$ of the Vibe function decreases with increase in the fraction of ethanol, indicating that, as the fraction of ethanol is increased, the rate of combustion is faster. This can be explained by the higher flame velocity of ethanol, which is $0.41 \mathrm{~m} / \mathrm{s}$ as compared to gasoline's flame speed of $0.31 \mathrm{~m} / \mathrm{s}[3,19]$. The simulation model performs a two-zone combustion analysis to obtain the pressure and temperature 
of the unburned gas, which are necessary to calculate $\mathrm{ON}_{\mathrm{Eff}}$ using Eq.[20] and facilitate calculation of $\mathrm{ON}_{\mathrm{Eff}}$ using the following equation:

$$
O N=100 *\left[\frac{1}{17.86} *\left(\int_{0}^{t_{c}} p^{1.7} * e^{\frac{-3800}{T}}\right) * d t\right]^{\frac{1}{3.402}}
$$

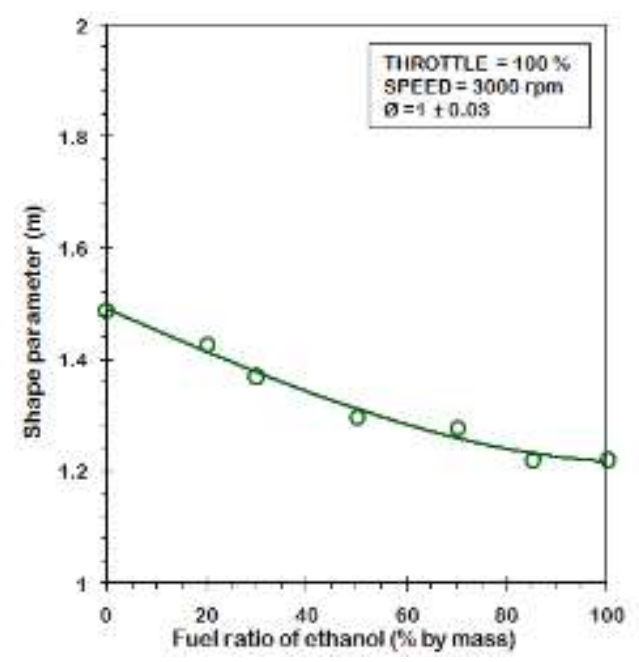

Figure 2. Shape parameter versus fuel ratio.

This equation is a rearranged form of Eq.(8) used by Kasseris and Heywood [5]. This model assumes the upper limit of integration in Eq.(10) as the time required for 85\% MBF, whereas the method used by Kasseris and Heywood [5] uses the crank angle occurrence of peak pressure. A crank angle occurrence comparison of the two different upper limits of integration showed that both peak pressures and $85 \% \mathrm{MBF}$ occur at very close crank angles. Figure 3 shows the MBF superimposed over the in-cylinder pressure trace and it can be seen that the crank angle occurrence of $85 \%$ MBF coincides with that of peak pressure. So the choice of time for $85 \% \mathrm{MBF}$ is considered valid and is used for this study. It may be noted that the $\mathrm{ON}_{\mathrm{Eff}}$ is the minimum octane number that is needed to work without knock at the given operating condition.

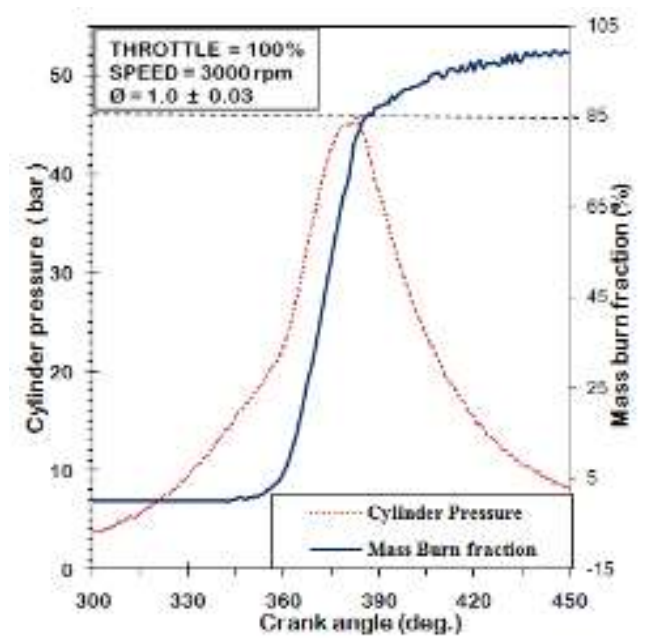

Figure 3. Crank angle comparison of peak pressure occurrence and $85 \% \mathrm{MBF}$. 
The antiknock potential obtained by injecting a pre-blended mixture using a single injector is studied through a slightly modified model. Since in the case of preblended injection a single injector is used, it was assumed that the fuel utilizes less heat from the valve and port surfaces and thus a greater fraction of fuel entering the cylinder is not evaporated. These effects were included in the model by making suitable changes to the port surface temperature and percentage evaporation of fuel in the manifold. These changes were made in accordance with the experimentally obtained volumetric efficiency.

\section{Model Validation}

The $\mathrm{ON}_{\text {Eff }}$ calculation can capture the effects of the actual operating conditions only if the $P$ and $T$ used in Eq.(10) represent the actual pressures and temperatures obtained during engine operation. Considering the importance of $P$ and $T$, the 1-D analytical model was validated to ensure that it accurately calculates these variables. The results obtained from the simulation model were compared with those of the experiments. Results used for comparison include the in-cylinder pressure trace, EGT and crank angle occurrence of peak pressures. Figure 4 shows the in-cylinder pressure traces of E85 ( $85 \%$ of the total fuel injected by mass is ethanol). It can be seen that the simulated in-cylinder pressure trace closely follows the experimentally measured in-cylinder pressure trace. This indicates that the pressure used in Eq. (10) for calculation of $\mathrm{ON}_{\mathrm{Eff}}$ closely represents the actual experimentally obtained pressure.

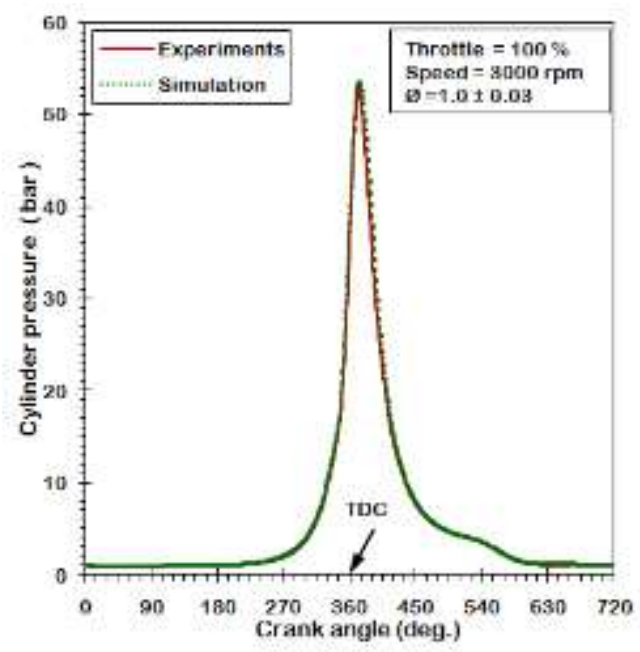

Figure 4. Cylinder pressure versus crank angle for E85.

The in-cylinder pressures of the remaining fuel ratios also closely follow their corresponding experimentally measured in-cylinder pressure traces. This can be observed from Figure 5, which compares:1) the experimentally obtained peak pressures with those obtained through simulations, and 2) the experimental and simulation obtained crank angle (CA) occurrence of peak pressures for the seven fuel ratios. Since the in-cylinder temperature $T$ used in Eq.(10) for calculation of $\mathrm{ON}_{\mathrm{Eff}}$ was not directly measured, it could not be validated explicitly. Instead, the EGT, which is proportional to the in-cylinder temperature, is considered for its validation. The comparisons of simulated EGT with experimental EGT are shown in Figure 6. The simulation model over-predicted the EGT, but the trend obtained in experimental measurements is 
followed. It can be seen that the EGT trend is sufficient to study the in-cylinder charge temperature. Overall, the comparison indicates that the model can be considered valid and is used for the calculation of $\mathrm{ON}_{\mathrm{Eff}}$.

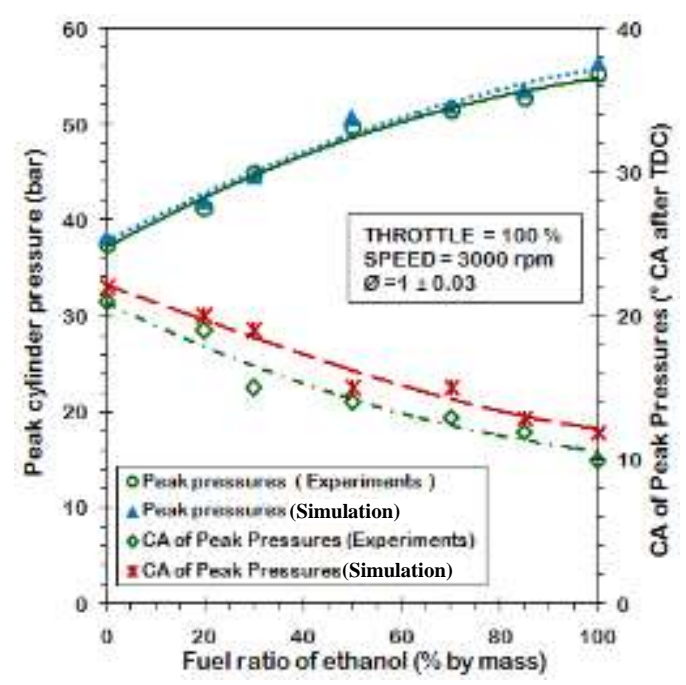

Figure 5. Peak pressures and their crank angle occurrence.

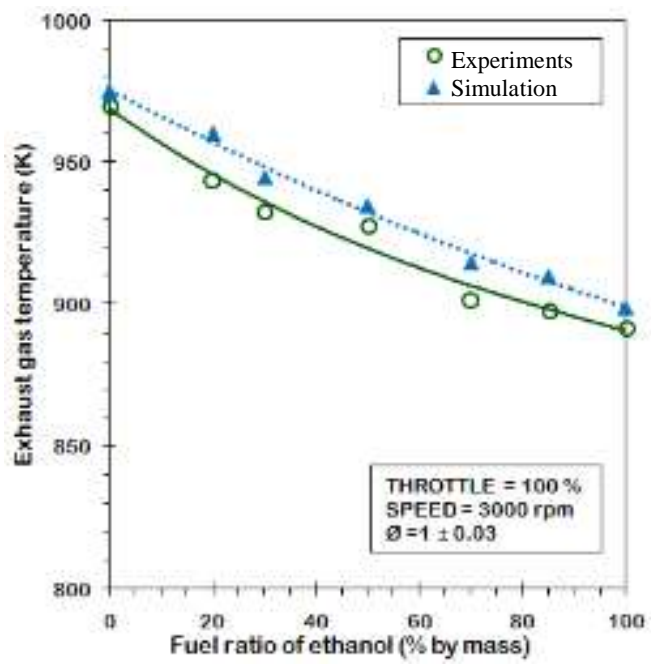

Figure 6. Simulated versus experiment obtained EGT for different fuel ratios.

\section{RESULTS AND DISCUSSION}

The in-cylinder pressures for three fuel ratios, E0 (only gasoline), E50, and E100, are shown in Figure 7. The use of higher fractions of ethanol results in higher in-cylinder pressures. This is because as the fraction of ethanol is increased it is possible to advance the spark timing without causing knock for best efficiency. Costa and Sodré [21] reported that the advanced spark timing and higher flame velocity of ethanol lead to an earlier combustion phasing and higher peak cylinder pressures, and this causes an increase in efficiency. Similar results have also been reported by Kumar, Khatri [22] and Bayraktar [23]. Figure 5 shows the trend followed by peak pressures and CA occurrence of peak pressures with increase in the ethanol fraction in the fuel. The unburnt charge temperatures obtained from the simulation model are shown in Figure 8. 
The temperature of the un-burnt charge is higher for higher fuel ratios, just like the pressures, and is again due to the faster combustion rate of ethanol-rich mixtures. Overall, the use of higher fractions of ethanol results in higher in-cylinder pressures and higher unburned charge temperatures. Since these values just correspond to knocking conditions, this implies that for higher fractions of ethanol, the un-burnt charge does not undergo auto-ignition even when present in more ignition-favourable conditions. Because knocking, as discussed above, is nothing but auto-ignition of charge, it indicates that higher fuel ratios have better antiknock qualities with higher auto-ignition temperatures, higher flame velocities being such qualities.

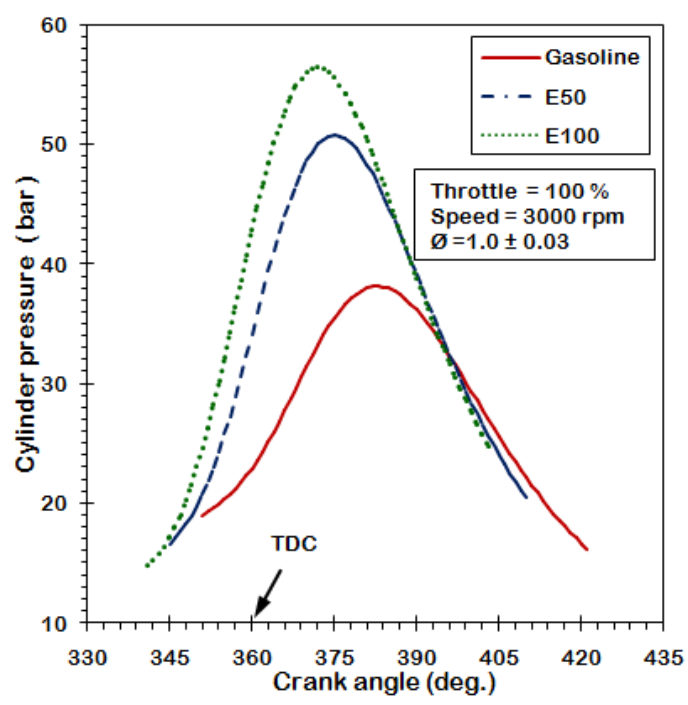

Figure 7. Simulated cylinder pressure vs. CA for gasoline, E50 and E100.

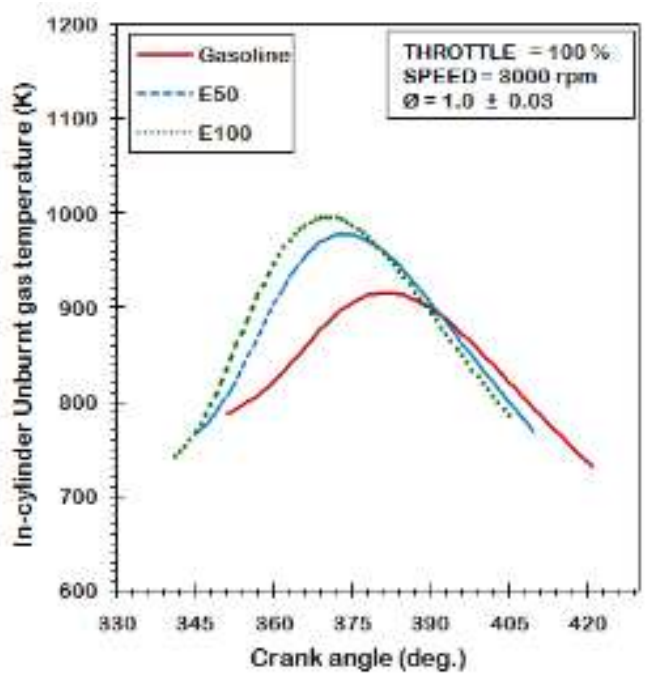

Figure 8. Simulated un-burnt gas temperatures vs. CA for gasoline, E50 and E100.

Since the $\mathrm{ON}_{\mathrm{Eff}}$ calculation from Eq.(10) utilizes the above discussed $P$ and $T$, it also reflects the antiknock benefits. It can be observed that substituting higher values of $P$ and $T$ in Eq.(10) will yield higher $\mathrm{ON}_{\text {Eff. The resulting }} \mathrm{ON}_{\text {Eff }}$ values are shown in Figure 9. It also shows an $\mathrm{ON}_{\mathrm{Eff}}$ comparison with RON obtained by Anderson, Leone 
[1]. The $\mathrm{ON}_{\text {Eff }}$ correlates well with the RON obtained by Anderson, Leone [1]. When compared with the RON values, the $\mathrm{ON}_{\mathrm{Eff}}$ values were lower by at most 4 units, but the trend obtained was the same. This shows that this method can predict the antiknock behaviour of an alcohol-gasoline mixture well. Increasing the fraction of ethanol increases the antiknock benefits, as $\mathrm{ON}_{\mathrm{Eff}}$ increases from 90 to 105 units when the ethanol quantity is increased from 0 to $100 \%$. The amount of increase in $\mathrm{ON}_{\mathrm{Eff}}$ with fuel ratio reduces from E50 onwards. This diminishing advantage in the antiknock potential can also be inferred from the un-burnt gas pressures and the temperature of different fuel ratios. Figure 8 indicates that the difference in temperatures of un-burnt charge is larger between E50 and E0 than between E50 and E100. Similar differences can be observed in the pressure traces in Figure 7. It may be noted that the knock-limited spark advance also does not change significantly after E50.

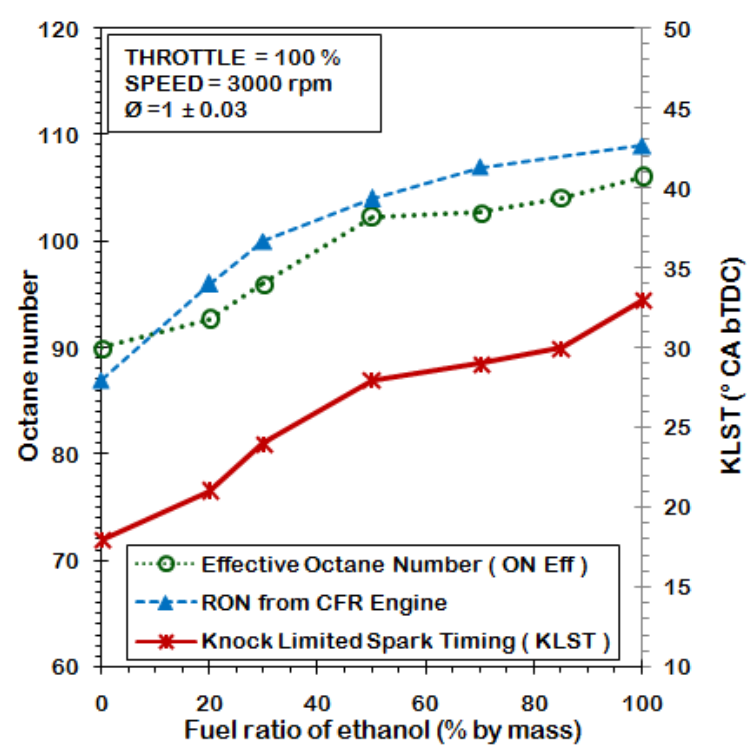

Figure 9. Octane numbers and knock-limited spark timing versus fuel ratio.

In the pre-blended case it was expected that the use of a single injector would result in less heat of evaporation from ports/wall surfaces in the manifold and thus lower in-cylinder charge temperatures. This would enable more advance of the spark timing without knock when compared to the case of simultaneous injection. As expected, when experiments were carried out using the E50 fuel ratio in both pre-blended and simultaneous injections, the spark advance for the pre-blended case was 2 degrees more than that of simultaneous injection. The resulting $\mathrm{ON}_{\mathrm{Eff}}$ of the pre-blended injection case was also higher than the $\mathrm{ON}_{\mathrm{Eff}}$ of the simultaneous injection case, but the difference in $\mathrm{ON}_{\mathrm{Eff}}$ is only 0.8 units. This shows that the pre-blended injection has only a slight advantage in mitigating knock when compared to the simultaneous injection.

\section{CONCLUSIONS}

The one-dimensional simulation with a two-zone combustion model indicates the presence of unburned charge at higher pressures and temperatures at the onset of knock while using high amounts of ethanol along with gasoline. The $\mathrm{ON}_{\mathrm{Eff}}$ values obtained from the simulations were close to the RON stated in literature. Both the $\mathrm{ON}_{\mathrm{Eff}}$ and the RON show that increasing the fraction of ethanol by mass in the fuel increases the 
antiknock benefits, but the benefit diminishes once the fraction of ethanol exceeds $50 \%$. So, considering only the benefits of antiknock, the use of $50 \%$ ethanol is recommended. The $\mathrm{ON}_{\mathrm{Eff}}$ of the pre-blended injection case was only slightly higher ( 0.8 units) than the $\mathrm{ON}_{\mathrm{Eff}}$ of the simultaneous injection case. This shows that simultaneous injection is equally effective in mitigating knock when compared to pre-blended fuel. Thus, simultaneous injection using two injectors as demonstrated in this work can effectively utilize alcohols along with gasoline with good antiknock capabilities. Also, this method can be utilized to capture the antiknock benefits including the effects of actual engine operating conditions.

\section{ACKNOWLEDGMENTS}

The authors thank M/s AVL India for providing the software (AVL Boost) to carry out this study.

\section{REFERENCES}

[1] Anderson JE, Leone TG, Shelby MH, Wallington TJ, Bizub JJ, Foster M, et al. Octane numbers of ethanol-gasoline blends: measurements and novel estimation method from molar composition. SAE Technical Paper No. 2012-01-1274; 2012.

[2] Heywood JB. Internal combustion engine fundamentals. New York: McGrawHill; 1988.

[3] Venugopal T, Ramesh A. Effective utilisation of butanol along with gasoline in a spark ignition engine through a dual injection system. Applied Thermal Engineering. 2013;59:550-8.

[4] Kasseris E, Heywood J. Charge cooling effects on knock limits in SI DI engines using gasoline/ethanol blends: Part 1-quantifying charge cooling. SAE Technical Paper No. 2012-01-1275; 2012.

[5] Kasseris E, Heywood J. Charge cooling effects on knock limits in si di engines using gasoline/ethanol blends: part 2-effective octane numbers. SAE Technical Paper No. 2012-01-1284; 2012.

[6] Stein RA, House CJ, Leone TG. Optimal use of E85 in a turbocharged direct injection engine. SAE Technical Paper No. 2009-01-1490; 2009.

[7] Ghobadian B, Najafi G, Nayebi M. A semi-empirical model to predict diesel engine combustion parameters. Journal of Mechanical Engineering and Sciences. 2013;4:373-82.

[8] Yusop AF, Mamat R, Mat Yasin MH, Ali OM. Effects of particulate matter emissions of diesel engine using diesel-methanol blends. Journal of Mechanical Engineering and Sciences. 2014;6:959-67.

[9] Azad AK, Ameer Uddin SM, Alam MM. A comprehensive study of DI diesel engine performance with vegetable oil: an alternative boi-fuel source of energy. International Journal of Automotive and Mechanical Engineering. 2012;5:57686.

[10] Ramasamy D, Yuan GC, Abu Bakar R, Zainal ZA. Validation of road load characteristic of a sub-compact vehicle by engine operation. International Journal of Automotive and Mechanical Engineering. 2014;9:1820-31. 
[11] Yusaf T, Hamawand I, Baker P, Najafi G. The effect of methanol-diesel blended ratio on $\mathrm{CI}$ engine performance. International Journal of Automotive and Mechanical Engineering. 2013;8:1385-95.

[12] Kamil M, Rahman MM, Bakar RA. Integrated simulation model for composition and properties of gases in hydrogen fueled engine. International Journal of Automotive and Mechanical Engineering. 2013;8:1242-155.

[13] Abdullah NR, Shahruddin NS, Mamat R, Ihsan Mamat AM, Zulkifli A. Effects of air intake pressure on the engine performance, fuel economy and exhaust emissions of a small gasoline engine. Journal of Mechanical Engineering and Sciences. 2014;6:949-58.

[14] Douaud A, Eyzat P. Four-octane-number method for predicting the anti-knock behavior of fuels and engines. SAE Technical Paper NO. 780080; 1978.

[15] Livengood $\mathrm{J}, \mathrm{Wu} \mathrm{P}$. Correlation of autoignition phenomena in internal combustion engines and rapid compression machines. Symposium (International) on Combustion. 1955; 5(1), 347-56.

[16] Boost A. Users guide. Version 2011. AVL LIST GmbH, Graz, Austria, Document. 2011.

[17] Ramasamy D, Bakar RA, Rahim MF, Noor MM. Comparative evaluation of a two stroke compressed natural gas mixer design using simulation and experimental techniques. Proceedings of the 4th IASTED Asian Conference on Power and Energy Systems, AsiaPES 20082008. p. 359-62.

[18] Boost A. Theory manual. AVL List Gmbh, Graz-Austria. 2011.

[19] Ramasamy D, Aik Soon K, Walker-Gitano Briggs H, Zainal ZA. Variation of airflow pattern through dissimilar valve lift in a spark ignition engine. Journal of the Chinese Institute of Engineers, Transactions of the Chinese Institute of Engineers,Series A/Chung-kuo Kung Ch'eng Hsuch K'an. 2013;36:1083-96.

[20] Kim Y, Peskin C. 2-D Parachute Simulation by the Immersed Boundary Method. SIAM Journal on Scientific Computing. 2006;28:2294-312.

[21] Costa RC, Sodré JR. Hydrous ethanol vs. gasoline-ethanol blend: Engine performance and emissions. Fuel. 2010;89:287-93.

[22] Kumar A, Khatri D, Babu M. An investigation of potential and challenges with higher ethanol-gasoline blend on a single cylinder spark ignition research engine. SAE Technical Paper No. 2009-01-0137; 2009.

[23] Bayraktar H. Experimental and theoretical investigation of using gasolineethanol blends in spark-ignition engines. Renewable Energy. 2005;30:1733-47. 